\title{
Role of Psychological Capital in Effective Management of Work-stress among Tertiary Institutions' Staff in Nigeria
}

\author{
John K. Aderibigbe* ${ }^{* 1}$, Themba Q. Mjoli ${ }^{1}$, Kolawole S. Adebisi² \\ 1 University of Fort Hare, South Africa \\ ${ }^{2}$ The Polytechnic, Ibadan, Nigeria \\ *201607467@ufh.ac.za
}

\begin{abstract}
Work-stress is synonymous to occupational stress. It is a common form of strain that is usually experienced by employees, in the course of performing their official duties and responsibilities. In the contemporary world of work, including the Nigerian work environment, work-stress is identified as a 'corporate epidemic'. Its symptoms are mostly observed physically, psychologically and socially in the lives of affected employees, while the negative effect of occupational stress is specifically, measured on employee performance and organizational effectiveness. It is for the above-described nature and effect of work-stress that this study examined the role of psychological capital in effective management of work-stress among the staff of tertiary institutions in Nigeria. It adopted the explanatory survey research design, purposive and convenience sampling techniques in sampling a total number of 202 (male $=116,57.4 \%$ and female $=86$, $42.6 \%$ ) academic and administrative staff of five (5) public and private tertiary institutions, in the western region of Nigeria, who served as participants in the study. All participants were Nigerians English speakers. Research participation eligibility was strictly based on the current enlistment of employees on the pay-roll of the institutions as at the time of the study. A structured validated questionnaire was used as an instrument. Hypotheses were stated and analyzed based on the data collected. Results revealed that the four psychological capital states jointly influenced work-stress management $F(4,197)=8.375 ; R^{2}=0.128 ; p<.05$; resilience $(\beta=0.145 ; \mathrm{t}=1.983 ; \mathrm{p}<.05)$ and optimism $(\beta=0.294 ; \mathrm{t}=3.756 ; \mathrm{p}<.05)$ independently influenced workstress management; optimism $(\mathrm{r}=.224, \mathrm{P}(.001)<.01)$, resilience $(\mathrm{r}=.350, \mathrm{P}(.000)<.01)$ and hope $(\mathrm{r}=.247, \mathrm{P}(.000)<.01)$ significantly correlated with work-stress management. The study concluded that psychological capital is one of the important factors that effectively helps in managing work-stress, and suggested that the management of institutions or organizations should sensitize employees on the importance of psychological capital in effective management of work-stress through seminars, trainings and conferences.
\end{abstract}

Keywords: Work-stress, psychological capital, management, tertiary institution, staff

\section{Introduction}

In the recent time, work-related stress has stimulated scientific research interest in Africa, because among life situations, the work or occupation stands out as an important source of stress, perhaps due to the amount of time spent at the work setting (Ekienabor, 2016). Hence, it is an unavoidable consequence of the modern life. Work-stress is a condition of strain that has a direct bearing on emotions, thought process and physical conditions of a person (Beheshtifar \& Nazarian, 2013). For two reasons, the study investigates the role of psychological capital in effective management of work-stress. First, because work-stress is a negative phenomenon that is associated with professions, which requires a positive state of the minds of employees, to effectively cope with and perform desirably at work. Secondly, the world of work is becoming more complex everyday giving to diversification, innovation, globalization, customer satisfaction and legal issues arising continually. These among others make it imperative for this study, to see to a strategic psychological intervention, which could effectively help in managing work related stress. Scientists have linked poor job satisfaction and challenges retaining employees in current employments to high levels of work-stress (Laschinger, 2011). The World Health Organization has also reported work-stress to be a global epidemic (WHO, 2010). Obviously, the consequence of an increasingly strenuous work environment is evident in the Nigerian Academic Sector, as cases of psychological breakdown and relapse remain elusive among Nigerian employees (Adetayo, Ajani \& Olabisi, 2014; Arogundade \& Lawal, 2016). Yet, extensive research over the years has focused more on identifying the stressors (Paillé, 2011; Brynien \& Igoe, 2016) but little scientific investigation has been conducted in the area of management of work-stress. 
In view of the above, the aims of the present study are twofold. The primary goal is to empirically examine the role of psychological capital (comprises of hope, self-efficacy, resilience and optimism) as a composite variable in an effective management of work-stress. The secondary goal on the hand, is to enlighten the general public about the importance of psychological capital in the management of stressful situations. In other words, the study's objective is to specifically investigate if hope, self-efficacy, resilience and optimism will independently and jointly influence work-stress management among employees of academic institutions in Nigeria. The study is significantly important to diverse areas of human endeavors. It will therefore benefit humanity in the following areas:

- The study will further promote the capacity of psychology of positivity in solving some existing human problems, through the means of psychological capital, which is a potent instrument of the positivists, to help the people out of their behavioral challenges most especially, in the corporate sector.

- Occupation stress is encompassing in effect and nature. It therefore, cannot be effectively managed or tackled with only the chemotherapeutic approach. It is for this reason that the present study investigates the effectiveness of a psychotherapy (psychological capital) in managing work-stress. Hence, positive findings in this study will yield practical suggestions by recommending psychological capital as a form of psychological coping mechanism to employee stress.

- Outcomes of the study will definitely evoke more attentions of scholars into this innovative area of investigation.

- Consequently, the study will increase the volume of literature on work-stress.

\section{Defining Terms}

Work-Stress Management: Work-stress management is defined in the present study as a strategic psychological intervention for coping with the perceived negative work conditions called stressors, which have negative mental and physical health-related consequences. Research shows that organizational and personal resources may facilitate employees' adjustment to the professional work environment (Laschinger, Grau, Finegan, \& Wilk, 2011).

Psychological Capital: Psychological capital is a composite variable, which comprises of four basic variables to be specific, optimism, resiliency, hope and self-efficacy. It refers to a person's positive mental state of advancement that is characterized by: (1) having confidence (self-efficacy) to require on and invest important push to prevail at testing undertakings, (2) making an encouraging ascription (optimism) about succeeding now and later on,(3) driving forward toward objectives (hope) and when fundamental diverting ways to objectives with a specific end goal to succeed and (4) at the point when assailed by issues and affliction, maintaining and ricocheting back and even past (resiliency) to accomplish achievement. Although, the over four componential variables of psychological capital have distinctive hypothetical points of view and definitions, taken together these four has been hypothetically created and generally tried as a state like positive center develop (Avey, Luthans \& Jensen, 2009).

\section{Literature Review}

Research on the effect of psychological capital on stress is very few. However, in an empirical investigation of psychological resources and strategies to cope with work-stress among 554 employees of different organizations in Israel, Rabenu and Yaniv (2017) sampled opinions of the study participants using a structured questionnaire, and analyzed the collected data accordingly with the Structural Equation Modelling. The outcome of the study shows that psychological resources (self-efficacy, resilience, hope and optimism) positively related to coping by change and by acceptance and negatively related to withdrawal. Similarly, HeeYun, Hyun-Ju, Yoonhyung and JinHee (2017) conducted a cross-sectional descriptive survey on the mediating role of psychological capital in the management of occupational stress among 457 nurses, in four veteran hospitals, South Korea. A structure questionnaire was used as a data collection instrument in the study, and the data gathered were analyzed using regression analysis, whose results indicate that psychological capital played a partial mediating role in the management of occupational stress. Similarly, Karmakar (2016) examined the concept of psychological capital through the following query: Does psychological capital promote the use of functional and dysfunctional coping strategy? According to the findings of Karmakar (2016)'s study, the senior and junior executives' employees vary with respect to their Coping strategy. The 
study reported further that there are some significant differences between senior and junior employees with respect to their positive psychological capital. Positive psychological capital has a significant positive correlation with the functional coping strategy (Karmakar, 2016). The study concludes that training and developing positive psychological capital among employees help them to deal with stressful situation assertively rather than avoiding it in order to promote positive attitude at the workplace.

Liu, Ren and Zhao (2016) conducted a related study on the connection between work-related stress and wellness among the junior administrative staff in universities from the perspective of social network (otherwise known as social capital and being the closely related to psychological capital). The study found that occupational stress has a noteworthy negative effect on their work-related well-being. However Social network produces a certain negative effect on occupational stress but a positive effect on occupational wellbeing (Liu, Ren \& Zhao, 2016). The conclusions got in this investigation give a reference for the junior administrative staff in colleges to adequately assuage the work-related stress and upgrade the professional well-being (Liu, Ren \& Zhao, 2016). Furthermore, Chou, Lee, \& Wu, (2016) found in their study of the relationship between resilience, emotion and work stress that there is a significant relationship between resilience and work stress. Based on the research findings, it is suggested that teachers should engage in more activities to raise resilience level and lower work stress. Kesari (2012) investigated the relationship between occupational-stress and psychological-capital among teachers in Durban, Kwazulu Natal Region of South Africa. The study found that there is a significant relationship between work-stress and psychological capital. Kesari (2012) reports further that psychological capital significantly stimulates positive practices in hectic occupational environments. The study also reports that psychological capital is a predictor of pleasure and meaning amongst teachers despite their stressful occupational field.

In addition, Kumar and Deo (2011) investigated work life of college staff and discovered that there was a significant difference in the perception of male and female participants. Kumar and Deo (2011)'s findings further uncovered that junior university staff experienced fundamentally more weight on the vast majority of the measurements of strain in contrast to the senior staff. However, female staff experienced more roles burden and inter-role distance stress as compared to their male colleagues. Based on the above literature, researchers stated the following hypotheses:

- Self-efficacy, resilience, optimism and hope will jointly and independently influence work-stress management.

- Psychological capital will significantly correlate with work-stress management.

- Female respondents will score significantly higher on work-stress management than their male counterparts.

\section{Methodology}

Research Design: The study adopted the explanatory survey research design, because it measured variables that are not directly observable, for which a survey was considered appropriate and none of the variables was actively manipulated. The independent variable was psychological capital (comprises of self-efficacy, resilience, optimism and hope) while work-stress management was the dependent variable.

Participants and Procedure: A total number of two hundred and two (202) male=116 (57.4\%) and female $=86(42.6 \%)$ academic and administrative staff of the below mentioned tertiary institutions participated in the study. All participants were Nigerians English speakers and were all employees of five (5) academic institutions (University of Ibadan, Lead City University, The Polytechnic, Ibadan, Federal College of Education (Special) and Emmanuel Alayande College of Education) in Nigeria. Participation eligible for the respondents was based on enlistment of employees on the pay-roll of the institutions. Researchers officially sought and obtained approvals and permissions of the management of the institutions through the registrars, before the commencement of the fieldwork. Furthermore, participants were approached individually in their various offices and their consents were sought through an informed consent form. This was accompanied with a brief explanation by the researchers, about the importance of the study. Hence, all the participants participated voluntarily. Moreover, identity of participants was confidentially managed, because researchers instructed participants not to divulge their names or staff numbers in the course of the data collection. In the same vein, the Convenience and Purposive sampling techniques were adopted in sampling the participants. A 
questionnaire was given to each of the participants to fill at their convenience. Some took the form home, filled and submitted to the researchers when visited again for a follow-up while others filled the questionnaire immediately in their offices and equally submitted directly to researchers. The process of administration and retrieval of questionnaire lasted for five (5) weeks. Among the two hundred and thirteen (217) questionnaire forms that were distributed, two hundred and two were perfectly completed and retrieved respectively. The remaining fifteen questionnaires were excluded on the account of missing data or information and lose. Hence, a total of two hundred (202) completely filled questionnaires were subjected to data analysis.

Participant Characteristics: Statistics revealed that sixty-five (65) (32.2\%) of the participants were academics while the other 137 (67.8\%) were non-academic staff. One hundred and seventy-nine (179) $(88.6 \%)$ were permanent staff while the remaining twenty-three (23) (11.4\%) were temporary (contract) staff. Participants' ages ranged from 20 years - 70 years: fifty-nine (59) (29.2\%) were within 20-30 years, sixty-three (63) (31.2\%) were within 31-40 years, sixty-eight (68) (33.7\%) were within 41-50 years, eleven (11) (5.4\%) were within 51-60 years and one (1) (0.5\%) was above 60 years old.

Measurements: A26-item modified version of Luthans, Avolio, Avey, and Norman (2007) psychological capital questionnaire by McGee, (2011) was used in measuring psychological capital. The construct consists of self-efficacy, hope-state, optimism-state and resilience-state sub-scales, with a 5-point response format ranging from 1 / (Strongly disagree) to 5/ (Strongly agree). Participants who indicated strongly agreed to a positive statement scored 5 while those who indicated strongly agreed to negative statements scored 1. Hence, a high total score represents a high level of psychological capital while a low total score represents a low level of psychological capital. McGee (2011) reports the following Cronbach Alpha coefficients for the scale: self-efficacy $=.91$, hope $=.86$, optimism $=.75$ resilience $=.76$ and .93 for the whole scale while this study reports Cronbach Alpha coefficients of (self-efficacy 0.82, hope 0.81, optimism 0.85 resilience State 0.68) 79. Similarly, a 4-item scale of occupational-stress management that was developed by Hansen, (1997) was used in measuring work-stress management. The response format of the scale consists of a 5-point Likert-type scale ranging from $1 /$ (strongly disagree) to $5 /$ (strongly agree). Participants who indicated strongly agreed to a positive statement scored 5 while those who indicated strongly agreed to negative statements scored 1. Hence, a high total score represents a high level of work-stress management while a low total score represents a low level of work-stress management. The author reported alpha-coefficient of 0.75 for the scale while the present study reports a Cronbach Alpha coefficient of .79.

Statistical Analysis: The two hundred and two (202) screened questionnaires were analyzed using the Statistical Package for Social Sciences (SPSS) software. Multiple regression analysis was used in analyzing hypothesis one. Pearson correlation analysis was used for hypothesis two while hypothesis three was analyzed using T-test of independent groups.

\section{Results}

Hypothesis one, which stated that self-efficacy, resilience, optimism and hope will jointly and independently influence work-stress management was analyzed using Multiple regression analysis. The results are presented in table 1 and 2 below:

Table 1: Multiple Regression Analysis Showing the Joint influence of Self-efficacy, Resilience, Optimism and Hope on Work-Stress Management

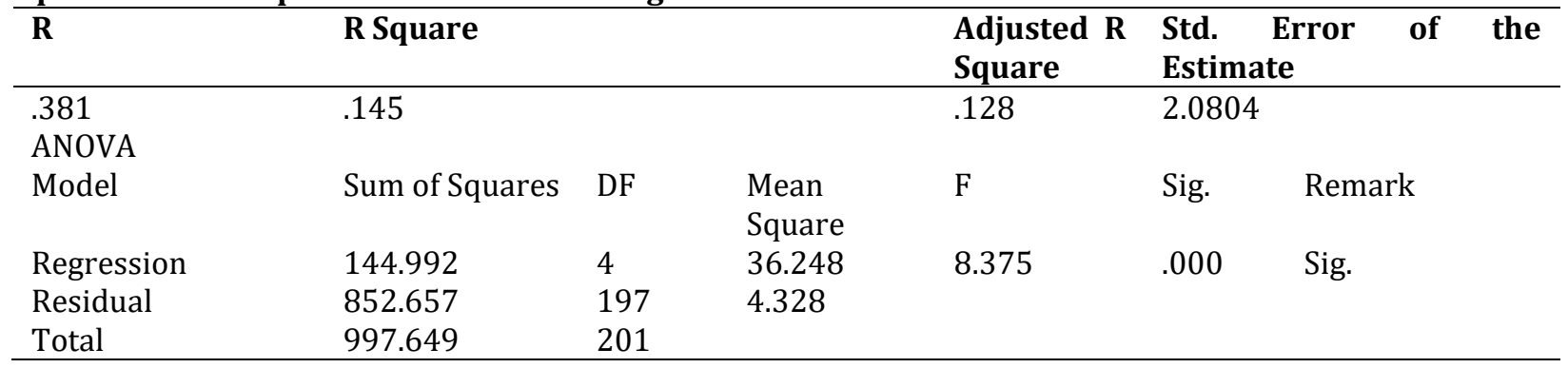


Results in the table 1 above shows that the four psychological capital sub-constructs jointly influenced workstress management. The table also shows a coefficient of multiple correlation $(\mathrm{R}=.381$ and a multiple adjusted $R^{2}$ of .128). This means that $12.8 \%$ of the occurrence of work-stress management is accounted for by the four psychological states when considered as a whole psychological capital. Furthermore, the other possible variables, which were not included in the study may have accounted for the remaining $87.2 \%$ variance. The significance of the composite contribution was tested at $\mathrm{P}<.05$. The table also shows that the analysis of variance for the regression yielded F-ratio of 8.375 (significant at 0.05 level). This implies that the joint contribution of self-efficacy, resilience, optimism and hope to the work-stress management is significant.

Table 2: Multiple Regression Analysis Showing the Relative Contribution of the Self-efficacy, Resilience, Optimism and Hope on Work-Stress Management

\begin{tabular}{lllllll}
\hline Model & $\begin{array}{l}\text { Unstandardized } \\
\text { Coefficient } \\
\text { B }\end{array}$ & $\begin{array}{l}\text { Std. } \\
\text { Error }\end{array}$ & $\begin{array}{l}\text { Stand. } \\
\text { Coefficient } \\
\text { Beta } \\
\text { Contribution }\end{array}$ & T & Sig. & Remark \\
\hline (Constant) & 8.608 & 1.321 & & 6.516 & .000 & Sig. \\
Self-efficacy & $-3.032 \mathrm{E}-02$ & .043 & -.051 & -.708 & .480 & Not sig. \\
Resilience & $9.244 \mathrm{E}-02$ & .047 & .145 & 1.983 & .049 & Sig. \\
Optimism & .173 & .046 & .294 & 3.756 & .000 & Sig. \\
Hope & $3.644 \mathrm{E}-02$ & .048 & .060 & .759 & .449 & Not sig. \\
\hline
\end{tabular}

Table 2 above reveals the independent contributions of the four psychological states to work-stress management, expressed as beta weights, viz: self-efficacy $(\beta=-.051, P>.05)$, resilience $(\beta=.145, P<.05)$, optimism $(\beta=.294, \mathrm{P}<.05)$ and hope $(\beta=.060, \mathrm{P}>.05)$ respectively. Hence, while resilience and optimism significantly and independently influenced work stress management in the study, self-efficacy and hope did not. Based on the results in tables 1 and 2 above and the interpretations, hypothesis one is partially confirmed. Hypothesis two, which stated that psychological capital will significantly correlate with workstress management was analyzed using Pearson Correlation Analysis. The results are presented in table 3 below:

Table 3: Pearson Correlation Analysis Showing the Relationship between Work-Stress Management, Self-Efficacy, Optimism, Resilience and Hope

\begin{tabular}{llllllll}
\hline & $\begin{array}{l}\text { Work-stress } \\
\text { management }\end{array}$ & Self-efficacy & Optimism & Resilience & Hope & Mean & S.D \\
\hline Work-stress & 1 & & & & & 14.62 & 2.23 \\
Management & & 1 & & & & \\
Self-efficacy & .095 & $.349^{* *}$ & 1 & & & 24.00 & 3.75 \\
Optimism & $.224^{* *}$ & $.271^{* *}$ & $.263^{* *}$ & 1 & & 21.35 & 3.49 \\
Resilience & $.350^{* *}$ & $.268^{* *}$ & $.327^{* *}$ & $.520^{* *}$ & 1 & 21.03 & 3.69 \\
Hope & $.247^{* *}$ & .267 & & & & \\
\hline
\end{tabular}

** Sig. at .01 level

From table 3 above, results show that there is a positive significant relationship between work-stress management and optimism $(\mathrm{r}=.224, \mathrm{P}(.001)<.01)$, resilience $(\mathrm{r}=.350, \mathrm{P}(.000)<.01)$ and hope $(\mathrm{r}=.247, \mathrm{P}$ $(.000)<.01)$. But there is no significant relationship between work-stress management and self-efficacy $(\mathrm{r}=.095, \mathrm{P}(.177)>.05)$. This implies that optimism, resilience and hope are significantly relevant in the management of work-stress. Based on the results and interpretations, hypothesis two is partially accepted. Hypothesis three, which stated that female respondents will score significantly higher on work-stress management than their male counterparts was analyzed using T-test of Independent Groups. The results are presented in table 4 below: 
Table 4: T-test of Independent Groups Showing the Difference in the means (x) of Male and Female Respondents on Work-Stress Management

\begin{tabular}{llllllll}
\hline Work-stress & N & Mean & Std. Dev. & Crit-t & Cal-t. & DF & P \\
\hline Male & 116 & 14.3448 & 2.1553 & & & & \\
& & & & 1.96 & 2.046 & 200 & .042 \\
Female & 86 & 14.9884 & 2.2829 & & & & \\
\hline
\end{tabular}

Table 4 above shows that there is a significant difference in the work stress management of male and female respondents (Crit- $\mathrm{t}=1.96$, Cal. $\mathrm{t}=2.046, \mathrm{DF}=200, \mathrm{P}<.05$ level of significance). Hence, female $(\mathrm{x}=15.00)$ respondents scored significantly higher on work-stress management than their male $(x=14.35)$ counterparts in the study. The hypothesis is therefore accepted.

Discussion: The main purpose of this study was to examine the role of psychological capital in effective management of work-stress. Based on the outcomes of the statistical analysis, results showed that the four elements of psychological capital (self-efficacy, resilience, optimism and hope) jointly influenced work-stress management among the staff of tertiary institutions in Nigeria. This implies that psychological capital as a concept of positivism, is a great asset and weapon that can help mankind to cope with and effectively manage stressful situations most especially, the stress that employees encounter at work. The results further explain that even though human activities are stressful generally, yet achievement of individuals' or organization's goals requires a person to unlock and develop the naturally endowed potentials in him, so as to constantly prevail over constraints and ensure of an enduring psychosocial well-being. Furthermore, the results revealed that among the four components of psychological capital, resilience, optimism and hope are the most significantly effective and relevant in the management of work-related stress while self-efficacy is not. This implies that the state of self-confidence alone is not reliable hence, it can collapse suddenly. Rather, individuals' resistance, perception or thought and faith levels count a lot when one is faced with challenges and strains. In other words, the quantity or level of such positive state-like potentials, which is possessed by a person, determines how able he or she will cope with and manage stressful situations at work effectively. It also explains that an employee who has a positive view and proactive approaches to life will easily cope with the dynamic environment of work.

The above results are supported with the findings of Rabenu and Yaniv (2017)'s study, which that psychological resources (self-efficacy, resilience, hope and optimism) positively related to coping by change and by acceptance and negatively related to withdrawal. Similarly, Hee-Yun, Hyun-Ju, Yoonhyung and JinHee (2017)'s study of the mediating role of psychological capital in the management of occupational stress among 457 nurses, in four veteran hospitals, South Korea shows that psychological capital played a partial mediating role in the management of occupational stress. The results further revealed that there is a significant difference in the work-stress management of male and female respondents. Hence, female respondents scored significantly higher on work-stress management than their male counterparts in the study. A critical thought over this result informs us that personal factors such as differences in the physical and bio-chemical compositions as well as the social responsibilities between male and female employees could have accounted for the variations in the management of work related stress between the two genders. When an employee perpetually encounters physically and cognitively demanding situations at work, with the pressure to deliver within a limited time frame, specified qualities and budget, such employees will continue to strive with his or her given targets, without minding the fact that, there is a limit to the amount of the physical resources, which the nervous system can supply at a time. Hence, having achieved a given target today for example, the next day another target is given and the trend continues throughout the week or month, it will result to accumulated stress. The work-stress in turn will stimulates some sense organ(s), from where adjacent sensory neurons are stimulated. The resultant neural impulse is carried to the brain through the appropriate sensory pathway(s). As the message gets to the hypothalamus (a brain structure and an endocrine gland), it causes the hypothalamus to release suitable releasing factors into the bloodstream. The hypothalamus would secret such releasing factors as the thyrotrophic-releasing factor and the corticotropic-releasing factor. These would be carried in the blood until it gets to the anterior pituitary gland, where it will cause the release of thyrotrophic hormone (TTH) and adrenocorticotrophic hormone (ACTH). These two hormones will individually stimulate their particular target organs (thyroid and adrenal cortex, respectively) leading to, 
among other results, increased energy production in the body, so that the individual is more ready to cope with the demanding situation.

Moreover, if the work pressures continue beyond the normal, which the body can cope with, then external supplementary resources are required for an individual to sustain his or her focus. However, when the body system reaches its threshold, it becomes weak and unresponsive. At this point, fatigue will set in and the affected individuals will begin to experience a negative related psychological state of burnout. The main point here is that, the capacity of the hypothalamus differs across genders. Male individuals are more aggressive in managing stressful situations. They may not be patient enough to fully exploit their natural and normal behavioral coping mechanisms before resulting to external alternatives, which most times do not effectively work, as against their females' counterpart approaches inform of relation therapy that keeps hope alive, sustains resistance and positive thoughts over situations. The present finding however, contrasts the findings from the study of Kumar and Deo (2011), which investigated work life of college staff and discovered that there was a significant difference in the perception of male and female participants. Kumar and Deo (2011)'s findings further revealed that junior college staff experienced significantly more stress on most of the dimensions of stress in comparison to the senior staff. However, female staff experienced more roles overload and inter-role distance stress as compared to their male counterparts.

\section{Conclusion}

In conclusion, evidence from the findings and discussions above showed that an effective management of work-stress partly depends on the possession of psychological capital. The study therefore, submits the following conclusions that:

- The ability of employees to effectively manage work-stress is a consequence of the collective influence of self-efficacy, hope, optimism and resilience.

- The amount or levels of hope, optimism and resilience possessed and exhibited by affected individuals determine how well the person will cope and manage work-stress effectively.

- Gender is not a strong factor in determining the effectiveness of stress management factor

- Psychological factors play effective in stress-intervention programs than demographic factors.

Recommendations: Based on the above findings, discussions and conclusions, the study makes the following recommendation that:

- The human resources development practitioners should proactively work to ensure that individual employees initiate, nurture, develop and sustain a positive state of their minds throughout the period of service.

- Governments at all levels, employers and scholars should play a more leading role in broadcasting the message of self-management through the approach of the positivist. The system of operation in organizations around the world today has drastically changed from routine to dynamism. It has now embraced technology, innovation, creativity and team work for better services. Hence, employees who really want to grow to the peak of their careers needs to be positive in thought, approaches, practices, skills and knowledge in order to minimize work-stress and effectively cope with the changing work environments.

- The management of academic institutions around the world, directors and managers of organization should design more effective manpower training programs, seminars, conferences and short-courses, to sensitize employees on the role of psychological capital in effective management of work-stress.

- It is also recommended that similar studies should be conducted in other sectors and countries. Hence, further studies in this area can be extended to private organizations, for a comparative analysis. Applying the above recommendations will significantly help in effective management of work related stress. 


\section{References}

Adetayo, J. 0., Ajani J. 0. \& Olabisi, O. (2014). An overview of the effects of job stress on employees' performance in Nigeria Tertiary Hospitals. Ekonomika, 60(4), 139-153.

Arogundade, O. T. \& Lawal, 0. (2016). The influence of perceived occupational stress on the organizational citizenship behavior of bankers in Ikeja, lagos state. European Scientific Journal, 12(17), 449-458.

Avey, J. B., Luthans, F. \& Jensen, S.M. (2009). Psychological capital: a positive resource for combating employees stress and turnover. Human Resource Management, 45, 677-693.

Beheshtifar, M. \& Nazarian, R. (2013). Role of occupational stress in organizations. Interdisciplinary Journal of Contemporary Research in Business, 4(9), 648-657.

Brynien, K. \& Igoe, A. (2016). Occupational stress factsheet. PEF Health and Safety Department: (800) 342$4306 \times 254$ or (518) 785-1900 × 254 .

Chou, M., Lee, H. \& Wu, H. (2016). Emotion, psychological resilience and work stress: a study among preschool teachers. European Journal of Psychological Research, 3(1), 8-15.

Ekienabor, E. E. (2016). Impact of job stress on employees' productivity and commitment. International Journal for Research in Business, Management and Accounting, 2(5), 124-133.

Hansen, M. (1997). Stress management skills. Tanglewood Research Evaluation. www.cehd.umn.edu/carei/reports/SIG/docs/CoreMeasures.PDF.

Hee-Yun, Y., Hyun-Ju, S., Yoonhyung, C. \& JinHee, K. (2017). Mediating role of psychological capital in the relationship between occupational stress and turnover intention among nurses at veterans' administration hospitals in Korea. Asian Nursing Research, 11(1), 6-12.

Karmakar, R. (2016). Positive psychological capital: Does this promote the use of functional and dysfunctional coping strategy? International Journal of Applied Research, 2(4), 22-27.

Kesari, S. (2012). Occupational Stress, Psychological Capital, Happiness and Turnover Intentions among Teachers. Department of Industrial Psychology, University of KwaZulu Natal.

Kumar, D. \& Deo, J. M. (2011). Stress and work life of college teachers. Journal of the Indian Academy of Applied Psychology, 37, 78-85.

Laschinger, H. K. S. (2011). Job and career satisfaction and turnover intentions of newly graduated nurses. Journal of Nursing Management. Advance online publication. doi: 10.1111/j.1365-2834.2011.01293.x

Laschinger, H. K., Grau, A. L., Finegan, J. \& Wilk, P. (2011). Predictors of new graduate nurses' well-being: Testing the job demands resource model. HealthCare Management Review. Advance online publication. doi: 10.1097/HMR. 0b013e31822aa456

Liu, W., Ren, L. \& Zhao, R. (2016). Exploration on the relationship between occupational stress and well-being of the junior Administrative staff in universities of china from the perspective of social network. Revista de Cercetare si Interventie Socialia, 53, 145-170.

Luthans, F., Avolio, B., Avey, J. \& Norman, S. (2007). Psychological capital: Measurement and relationship with performance and satisfaction. Personnel Psychology, 60, 541-572.

McGee, E. A. (2011). An examination of the stability of positive psychological capital using frequency-based measurement. University of Tennessee, Knoxville Trace: Tennessee Research and Creative Exchange, 1112.

Nelson, D. R. \& Sutton, C. (1990). Chronic work stress and coping: A longitudinal study and suggested new directions. Academy of Management Journal, 33(4), 859-869.

Paillé, P. (2011). Stressful work, citizenship behavior and intention to leave the organization in a high turnover environment: Examining the mediating role of job satisfaction. Journal of Management Research, 3(1), 1-14.

Rabenu, E. \& Yaniv, E. (2017). Psychological resources and strategies to cope with stress at work. Int. J. Psychol. Res, 10(2), 8-15.

WHO. (2010). Healthy Workplaces: A model for action for employers, workers, policymakers and practitioners. Geneva: WHO. 